
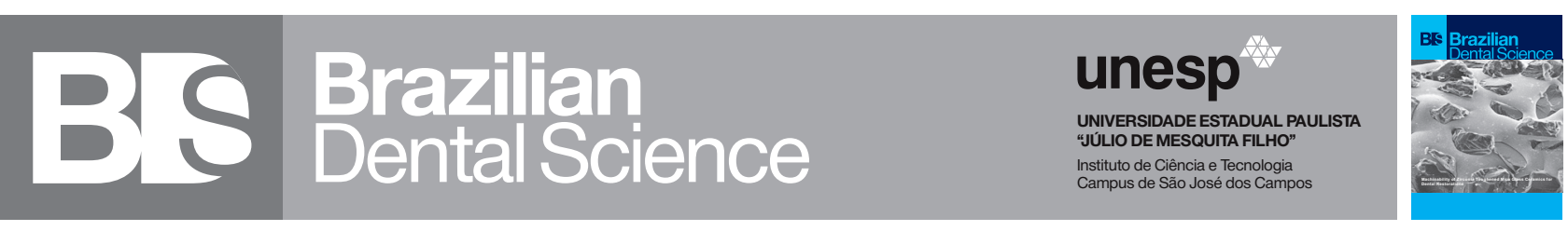

\title{
Color Stability of Bulk Fill Composite Resins Submitted to Coffee Staining
}

Estabilidade de cor de resinas bulk fill submetidas a manchamento com café

Beatriz Maria De ARRUDA ${ }^{1}$, Julio Cesar BASSI ${ }^{2}$, Rafael Pino VITTI ${ }^{1}$, Renata Siqueira SCATOLIN ${ }^{3}$

1 - Herminio Ometto University Center, School of Dentistry, Araras-SP, Brasil.

2 - Santa Cecília University, School of Dentistry, Santos-SP, Brasil.

3 - Herminio Ometto University Center, School of Dentistry, Departamento de Odontologia, Araras-SP, Brasil.

\section{ABSTRACT}

Objective: The aim of this in vitro study was to evaluate the color stability of different bulk fill composite resins after extrinsic staining with coffee. Material and Methods: Forty-eight disk-shaped specimens $(6 \mathrm{~mm}$ diameter x $4 \mathrm{~mm}$ thick) of each composite resin were prepared for color change test. The composite resins were divided into 4 groups $(n=12)$ : one conventional composite resin (Filtek Z250) and three bulk-fill composite resins (Filtek Bulk Fill, Aura Bulk Fill, and Opus Bulk Fill). The samples were stained with $20 \mathrm{~mL}$ coffee solution for 7 days, with the solution being replaced every $24 \mathrm{~h}$. The color change analysis was performed using a spectrophotometer, according to the CIE Lab formula. Data were analyzed using the Analysis of variance (ANOVA) and Tukey HSD tests $(\alpha=0.05)$. Results: The results revealed significant differences in color change among the composite resins tested $(\rho<0.0001)$. The Aura Bulk Fill and Opus Bulk Fill showed the highest color change values. Conclusion: Thus, all the resins analyzed were susceptible to extrinsic staining with coffee, and the Filtek Bulk Fill showed the lowest color change value.

\section{KEYWORDS}

Color; Composite resins; Dentistry.

\section{RESUMO}

Objetivo: O objetivo deste estudo in vitro foi avaliar a estabilidade da cor de diferentes resinas compostas bulk fill após coloração extrínseca com café. Material e Métodos: 48 corpos-de-prova em forma de disco $(6 \mathrm{~mm}$ de diâmetro x $4 \mathrm{~mm}$ de espessura) de cada resina composta foram preparados para o teste de alteração de cor. As resinas compostas foram divididas em 4 grupos $(n=12)$ : uma resina composta convencional (Filtek Z250) e três resinas compostas bulk-fill (Filtek Bulk Fill, Aura Bulk Fill e Opus Bulk Fill). As amostras foram coradas com $20 \mathrm{~mL}$ de solução de café por 7 dias, sendo a solução substituída a cada 24 horas. A análise da mudança de cor foi realizada em espectrofotômetro, de acordo com a fórmula CIE Lab. Os dados foram analisados por meio dos testes de Análise de Variância (ANOVA) e Tukey HSD ( $\alpha=0,05)$. Resultados: Os resultados revelaram diferenças significativas na mudança de cor entre as resinas compostas testadas $(\rho<0,0001)$. A Aura Bulk Fill e a Opus Bulk Fill apresentaram os maiores valores de alteração de cor. Conclusão: Assim, todas as resinas analisadas foram suscetíveis à coloração extrínseca com café, sendo que a Filtek Bulk Fill apresentou o menor valor de alteração de cor.

\section{PALAVRAS-CHAVE}

Cor; Resinas compostas; Odontologia. 


\section{INTRODUCTION}

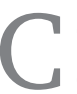
omposite resins are outstanding in the dental clinic, especially for their ability to mimic the appearance of natural teeth, in addition to having good physical and mechanical properties. However, because these materials are placed in the oral environment, they may be subjected to degradation, staining, and loss of mechanical properties over time [1], directly affecting the longevity of these restorations [2].

Thus, an important aspect to be observed is the staining of restorations, which may be caused by intrinsic factors that are related to the composition of the restorative material, and to extrinsic factors such as the ingestion of pigmenting foods that consequently cause changes in the surface of these composites. This applies particularly to composites that are more porous and susceptible to plaque accumulation, gingival inflammation and an aesthetic deficiency of restorations [3].

The incremental technique, most frequently used among dentists for performing direct restorations in posterior teeth, is performed with conventional composite resins and it does not depend on the operator's capacity and ability to manipulate the material. Insertions in increments of up to $2 \mathrm{~mm}$ are performed at the cavity margins with the aim of reducing the stresses caused by polymerization shrinkage [4]. However, this technique has some disadvantages, such as the total length of time taken to perform the restoration, because each increment needs to be photopolymerized individually, and the possibility of bubbles and voids forming in the restoration [5].

Recently, resins called Bulk Fill were launched on the marked in two formulations: low viscosity and high viscosity. The low viscosity types are indicated as a base for restorations and they require an increment of up to $2 \mathrm{~mm}$ of a conventional resin on top of their layer to ensure increased wear resistance [6]. The high viscosity resins may be inserted into the entire cavity in one single increment. These have properties, such as microtensile strength and marginal adaptation, similar to those of conventional composite resins [7-9]; however, they differ in relation to the insertion technique. This technique allows professionals to insert Bulk Fill resins into the cavity in one single increment of up to 4-5 $\mathrm{mm}$, optimizing the clinical working time [10]. More reactive photoinitiators were incorporated into these composites, which allow greater polymerization depth, and monomers were included, which work as modulators of the polymerization reaction, controlling the stresses, and promoting good bond strength between the tooth structure and the restorative material $[11,12]$. These changes in composition, may however, be related to the color change of the resins when they come into contact with pigmenting agents.

Therefore, this study aimed to assess the in vitro color stability of different bulk fill composite resins after simulations of extrinsic staining with coffee, since similar factors may compromise the clinical longevity of restorations, often indicating their early replacement.

\section{MATERIALS AND METHODS}

\section{Experimental design}

It was a causality study and the sample included 48 resin discs $(n=12)$ produced in a matrix measuring $6 \mathrm{~mm}$ in diameter and $4 \mathrm{~mm}$ thick. The experimental groups were divided into 4 groups: a conventional composite resin (Filtek Z250 - 3M ESPE, Sumaré-SP, Brazil) and three bulk-fill restorative materials used for restoring posterior teeth (Filtek Bulk Fill- 3M ESPE, Sumaré-SP, Brazil; Aura Bulk Fill- SDI, São Paulo-SP, Brazil and Opus Bulk Fill- FGM, Joinville-SC, Brazil). The outcome variable was the colorimetric analysis of color change, by using a spectrophotometer to perform quantitative analysis of color. 


\section{Sample collection}

Forty-eight resin discs measuring $6 \mathrm{~mm}$ in diameter and $4 \mathrm{~mm}$ thick were produced in shade A2. The matrix for producing the discs was performed in a precision workshop to ensure the standardization of samples. The composite resins were inserted using a dual titanium spatula (Millennium, Golgan, São Paulo-SP, Brazil). To obtain a regular surface, a polyester strip (K-Dent - Quimidrol, Joinville-SC, Brazil) and a glass plate with a $500 \mathrm{~g}$ load on it were placed on the sample surface for 30 seconds to allow the excess material to flow out and leave the surface smooth and standardized. The glass plate was removed and polymerization was performed with a light polymerizing unit (RadiiCal SDI, Victoria, Australia), at a distance of 5 $\mathrm{mm}$ [13] for the time determined by each of the resin manufacturers.

After fabricating the samples, they were subjected to finishing and polishing with a flexible finishing disc (FGM, Joinville-SC, Brazil) and polishing paste (FGM, Joinville-SC, Brazil). This procedure was performed obeying the sequence of finishing and polishing discs in descending order, using the time determined for each granulation: coarse (5 s), medium (5 s), fine (20 s). The polished were realized with felt discs (FGM, Joinville-SC, Brazil) and Diamond Excel paste (FGM, Joinville-SC, Brazil) for 20 $s$ [14]. The standard speed was padronized (15.000 rpm) and the discs were replacing after every five specimens. In between granulations, the specimens were rinsed with air-water spray for 10 seconds. At the end of the process, the specimens were taken to the ultrasound bath (Ultrasonic Cleaner 1440 Plus; Odontobrás, Ribeirão Preto-SP, Brazil) containing distilled, water for 20 minutes, to remove the debris deposited on the surface.

The composite resins used and the relevant information about each type were described in Table I.
Table I - Materials and their composition used in this study (Filtek 250; Filtek Bulk Fill; Aura Bulk Fill and Opus Bulk Fill).

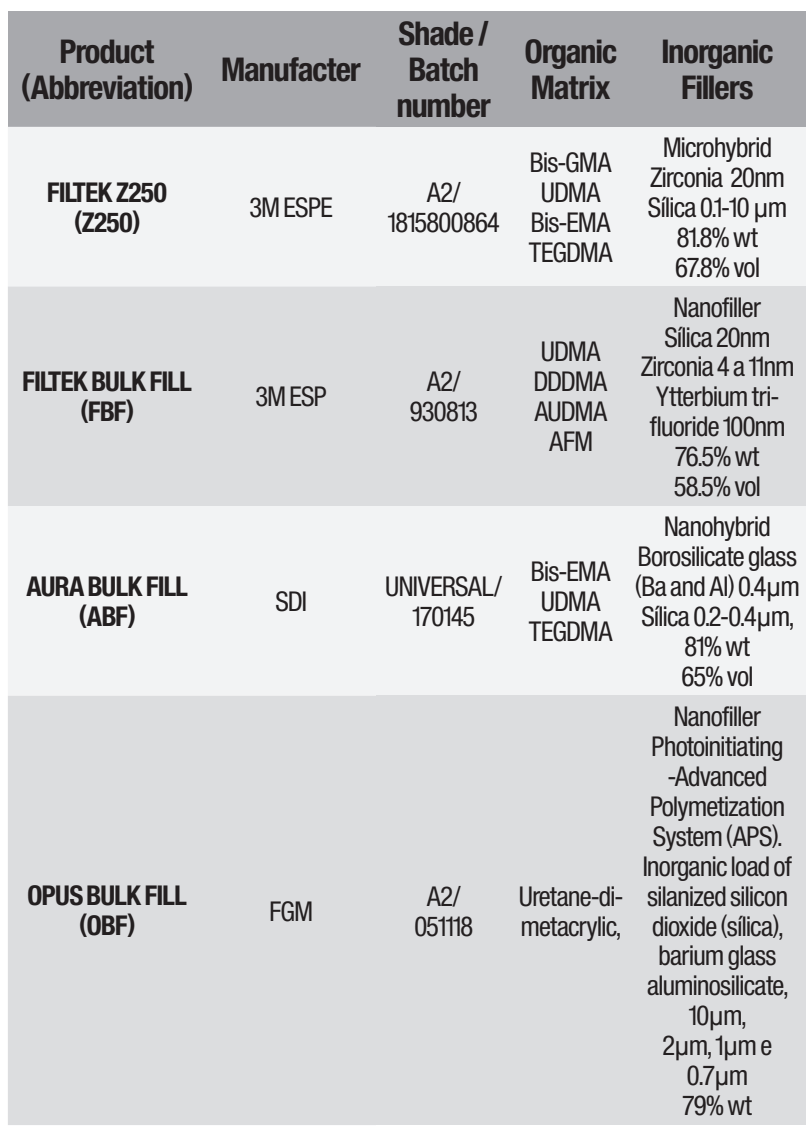

\section{Color change analysis}

The specimens were manipulated with clinical tweezers to prevent the samples from coming into direct contact with the operator's hands. Before the analyses, the specimens were dried with absorbent paper to prevent moisture from interfering in the values of color change.

For obtaining the color values, the spectrophotometer was first calibrated with the measurement of a pure white standard and pure black box. Next, each sample was positioned on a white tile to standardize the color readouts.

The color of each specimen was read two times: 1 . Before starting the immersion in staining solutions and 2. after the extrinsic staining with coffee. The analyses were performed by means of a SP62S spectrophotometer with QA Master 
I software (X-Rite Incorporated-Neu-Isenburg, Germany), a focal aperture of $4 \mathrm{~mm}$ and sphere geometry of measurement $\mathrm{d} / 8^{\circ}$ of illumination, observation angle of $10^{\circ}$, and wavelength between 400 and $700 \mathrm{~nm}$. The values obtained were shown by the device and later registered on a computer.

The CIE L*a*b* system uses three parameters to define color: luminosity, shade, and saturation. The $\mathrm{L}^{*}$ refers to the luminosity coordinate (grey scale) with values from zero (black) to 100 (white). The values of $\mathrm{a}^{*}$ and $\mathrm{b}^{*}$ are the chromaticity coordinates in the red-green and yellow-blue axes, respectively. Positive a* values indicate deviation of chromaticity toward the red shade and negative values indicate deviation toward the green shade. Similarly, positive $b^{*}$ values indicate deviation toward the yellow shade and negative values indicate deviation toward the blue shade [15].

After assessing the color of each sample at the time intervals determined, the $\Delta \mathrm{L}^{*}, \Delta \mathrm{a}^{*}$, and $\Delta \mathrm{b}^{*}$ values were calculated, which were the differences in $\mathrm{L}^{*}, \mathrm{a}^{*}$, and $\mathrm{b}^{*}$ values between the baseline and after staining.

The $\Delta \mathrm{E}^{*}$ (amount of color change of a sample) was calculated using the following formula:

$$
\Delta \mathrm{E}^{*}=\sqrt{\left(\Delta \mathrm{L}^{*}\right)^{2}+\left(\Delta \mathrm{a}^{*}\right)^{2}+\left(\Delta \mathrm{b}^{*}\right)^{2}}
$$

\section{Staining of samples}

The process of staining the resin specimens was performed with a coffee solution (Nescafé Original Extra Forte; Nestlé, Araras-SP, Brazil) in the ratio of $200 \mathrm{~mL}$ of water to $2 \mathrm{~g}$ of powder. The samples were immersed individually in 20 $\mathrm{mL}$ of staining solution in an incubator at $37^{\circ} \mathrm{C}$ for 7 days [16]. The solution was daily changed. The samples were washed for one minute before receiving a new solution and finally the staining, to remove any debris at the resin surface.

\section{Statistical analysis}

For interpretation of the color differences, 3.3 units were used, which has been reported as the clinical acceptability threshold [17].

The results obtained for $\Delta \mathrm{L}^{*}, \Delta \mathrm{a}^{*}$, $\Delta \mathrm{b}^{*}$, and $\Delta \mathrm{E}^{*}$ were assessed independently, according to the Concepts of Classical Statistics, after the exploratory analysis of the data. The Kolmogorov-Smirnov test was performed to verify data normality. Considering that the data were parametric, one-way analysis of variance (ANOVA) was performed and the means were compared by means of the Tukey HSD test.

For the analyses, the BioEstat 5.0 software was used at 5\% significance level.

\section{RESULTS}

Significant changes were found in $\Delta \mathrm{E}$, $\Delta \mathrm{L}, \Delta \mathrm{b}$, and $\Delta \mathrm{a}$ values of the resins among the different groups. (Table II).

It can be observed with the $\Delta \mathrm{E}$ values, that all groups showed chromatic changes, clinically visible $(\Delta \mathrm{E}>3.3)$. Group FBF had the lowest average color variation after staining with coffee, differing significantly from the other groups. Group Z250 showed color change values lower than those of Groups $\mathrm{ABF}$ and $\mathrm{OBF}$. Groups ABF and OBF did not differ significantly between them.

The analysis of delta L showed the same behavior of the groups as was shown in the analysis of delta E, with greater differences in luminosity values (darkening) for Groups ABF and OBF, followed by Groups Z250 and FBF.

The comparison of delta B showed greater changes in the yellow shade values for Group $\mathrm{OBF}$, and smaller changes for Group FBF.

In the delta $\mathrm{A}$ analysis, greater changes in the red shade values were found for Group $\mathrm{ABF}$, and lower changes for Group Z250. 
Table II - Mean ( $\pm \mathrm{SD}$ ) of $\Delta \mathrm{E}, \Delta \mathrm{L}, \Delta \mathrm{b}, \Delta \mathrm{a}$ of resin samples after staining with coffee

\begin{tabular}{|ccccc|}
\hline Groups & $\boldsymbol{\Delta} \mathbf{E}$ & $\boldsymbol{\Delta L}$ & $\boldsymbol{\Delta} \mathbf{b}$ & $\boldsymbol{\Delta} \mathbf{a}$ \\
\hline Z250 & $7.316(0.827) \mathrm{B}$ & $-6.983(0.780) \mathrm{B}$ & $1.128(1.827) \mathrm{AB}$ & $0.521(0.491) \mathrm{C}$ \\
\hline FBF & $6.198(0.639) \mathrm{C}$ & $-5.978(0.603) \mathrm{C}$ & $0.176(0.705) \mathrm{B}$ & $1.478(0.260) \mathrm{B}$ \\
\hline ABF & $9.395(1.129) \mathrm{A}$ & $-8.976(1.112) \mathrm{A}$ & $0.640(0.863) \mathrm{AB}$ & $2.558(0.328) \mathrm{A}$ \\
\hline OBF & $10.034(1.180) \mathrm{A}$ & $-9.608(1.038) \mathrm{A}$ & $1.936(1.525) \mathrm{A}$ & $1.623(0.372) \mathrm{B}$ \\
\hline
\end{tabular}

Distinct capital letters in a same column indicate significant differences $(\rho<0.05)$.

\section{DISCUSSION}

This study aimed to evaluate the color stability of bulk fill composite resins when submitted to extrinsic staining, as these stains can damage the clinical performance of direct restorations, leading to further wear of tooth structure by the need for successive replacements of restorative material.

The color change can be evaluated visually - a subjective method, or by instrumental techniques, with the use of a spectrophotometer according to the CIE L* a* b* system, to evaluate and measure chromaticity for determining small color differences. In this study, the color variation values $(\Delta \mathrm{E})$ were higher than 3.3 in all groups, considered a limit value for acceptability of composite resin color change [17]. Changes such as these, which interfere with color stability, may be linked to intrinsic and / or extrinsic factors. The former are related to the composition of the restorative material [18], whereas the latter relate to the accumulation of plaque and absorption of pigments by contamination from external sources [19].

The choice of coffee as a staining solution was attributed to the large consumption of this drink by the population and its high pigmentation potential $[20,21]$. This fact was also observed in the present study, in which all groups suffered color change values $(\Delta \mathrm{E})$ of over 6 . The reason why coffee easily changes the color of composite resins is because the polarity and yellow pigments of coffee have a strong affinity for polymers $[3,22]$. This justified the increase in the values of coordinate $\mathrm{b}^{*}$ tending towards yellow when submitted to this staining.

The staining protocol simulated a period of coffee consumption by one person in 7 months. According to the coffee manufacturer, the average time it takes to drink a cup of coffee is around 15 minutes, and the average consumption is 3.2 cups of coffee per day. Thus, one day of storage in this solution for a period of 24 hours corresponded to the simulated time of consumption of 1 month [23,24].

Although all groups showed clinically visible color change, lower change values were observed for Group FBF. The size, shape, type and amount of the filler particles are related to the color change as well as staining of the composite resin $[25,26]$. Small filler particles are less prone to water aging discoloration than large filler particles. However, it is important to emphasize that the amount of filler particles is also responsible for discoloration, since the resin composite can absorb more water [27]. Furthermore, the light incident on the composite resin is not fully transmitted. A fraction of the light is lost due to several factors, such as intrinsic absorption, pores, and roughness, affecting the optical properties. The transmittance of light decreases exponentially with the increase in absorbance (Beer-Lambert law), affecting the reflectance and, consequently, the color coordinates [28]. It could explain the results between the composite resins evaluated with similar amount of the filler particles (Table II). $\mathrm{ABF}$ and $\mathrm{OBF}$ have smaller filler particles than Z250, but they showed the highest means values of color changes. This result may be related to the resin matrix present in these composites. The lower change color observed for Group FBF may be related to absence of Bis-GMA and TEGDMA monomers in the composition (Table I). Some studies showed high levels of discoloration in the composite resins that have these monomers $[16,22]$. Due to the hydrophilic characteristic of these monomers, the composite resins that contain them are more susceptible to staining; 
because they increase water sorption, they also increase the sorption of other fluids $[19,29]$.

When Group ABF and Group OBF resins were compared, there were no significant differences in color change, but they showed higher values of staining than those of Group FBF. These results could perhaps also be linked to the degree of conversion of these resins. The differences in the composition of the organic matrix, as well as the density, size and distribution of particles, contribute to significant differences in the degree of conversion between restorative composites [30].

Goncalves et al. (2018) [31] compared the degree of conversion of different composite resins and observed that Group FBF obtained higher degree of conversion values when compared with Group ABF. Factors such as these could cause color instability in restorations due to deficiency in polymerization, contributing to the absorption of coloring substances [32]. The same is believed to have happened for Group OBF. Even with the use of a new APS initiation system (Advanced Polymerization System), the results indicated that this strategy may not have been sufficient to provide an effective polymerization of this resin in $4 \mathrm{~mm}$ increments. The composition of its resin matrix was not well described by the manufacturer, which made it difficult to perform some comparisons.

The difference in luminosity (delta L) between groups was the same as it was for color change (delta E), with higher darkening values (decrease in $\mathrm{L}^{*}$ ) for groups that underwent more extensive staining (Groups ABF and OBF). Samra et al. (2008) [33] in his work, pointed out that the decrease in luminosity values was critical for color stability and clinical success, because the human eye perceived these differences more easily, since there were a much higher number of cells (rods) responsible for black and white vision than those of the cells responsible for color vision (cones).

Although all resins showed a color change with values considered clinically visible when submitted to staining with coffee, Group FBF showed the least color change. Therefore, it should be taken into account that this in vitro study had some limitations such as tooth brushing procedures that would be performed in a clinical situation, which could minimize the effects of staining solutions under composites [34]. Thus, the authors suggest that in vivo studies should be conducted to assess the color stability of bulk fill composite resins in the oral environment.

\section{CONCLUSION}

All the resins analyzed were susceptible to extrinsic staining with coffee, and the Filtek Bulk Fill showed the lowest color change value.

\section{Acknowledgments}

The authors would like to thank the State of São Paulo Research Foundation (FAPESP) for the scholarship awarded (Proc No. 2018/206791), and University of São Paulo, for authorization to use the equipments.

\section{REFERENCES}

1. Opdam NJ, Van de Sande FH, BronkhorstE, Cenci MS, Bottenberg P,PallesenU, Gaengler P, et al. Longevity of posterior composite restorations: a systematic review and meta-analysis. J Dent Res. 20140ct; 93(10):943-9.

2. Tavangar M, BargheriR,Kwon TY,Mese A,Marton DJ. Influence of beverages and surface roughness on the color change of resin composites. J Investig Clin Dent 2018 Aug;9(3):1-8.

3. Um CM, Ruyter IE. Staining of resin-based veneering materials with coffee and tea. Quintessence Int. 1991May;22(5):377-86.

4. Bicalho AA, Valdívia AD, Barreto BC, Tantbjiroin D, Versluis A, Soares CJ. Incremental filling technique and composite material-part ll: shrinkage and shrinkage stresses. Oper Dent. 2014 Mar - Apr;39(2):83-92.

5. Soares CJ, Rosatto CMP,Carvalho VF, Bicalho AA, Henriques J, Faria-E-Silva AL. Radiopacity and Porosity of Bulk-fill and Conventional Composite Posterior Restorations-Digital X-ray Analysis. Oper Dent. 2017 Nov - Dec;42(6):616-25.

6. Van ende A, De Munck J, Lise DP, Van Meerbeek B. Bulk-Fill Composites: A Review of the Current Literature.J Adhes Dent. 2017 Feb;19(2):95-109.

7. Bayraktar Y, Ercan E, Hamidi MM, Colak H. One-year clinical evaluation of different types of bulk-fill composites. J Investig Clin Dent. 2016 May;8(2):1-9.

8. Yazici AR, Antonson SA, KutukZB, Ergin E. Thirty-Six-Month Clinical Comparison of bulk fill and Nanofill Composite Restorations. Oper Dent.2017 Sep -0ct;42(5):478-85. 
9. Heck K, Manhart J, Hickel R, Diegritz C. Clinical evaluation of the bulk fill composite Qui Xfil in molar class I and II cavities: 10-year results of a RCT.Dent Mater.2018 Apr;34(6):138-47.

10. Bellinaso MD, Soares FZM, Rocha RO. Do bulk-fill resins decrease the restorative time in posterior teeth? A systematic review and meta-analysis of in vitro studies. J Investig Clin Dent. 2019;10:e12463.

11. Fronza BM, Rueggeberg FA, Braga RR, Mogilevych B, Soares LE, Martin AA, etal. Monomer conversion, microhardness, internal marginal adaptation, and shrinkage stress of bulk-fill resin composites. Dent Mater. 2015 Dec;31(12):154251.

12. Ostapiuk M, Tarczydlo B, Surowska B, Orlowski M, Tymczyna B, Bachanek T, et al. Qualitative analysis of the margins of restorations made with different filling resins. Micros Res Tech. 2018 Aug;81(8):823-31.

13. Aromaa MK, Lassila LVJ, Vallittu, PK. Effect of Distance on Light Transmission Through Polymerized Resin Composite. Eur J Prosthodont Restor Dent. 2017 Aug;25(3):131-5.

14. Silva Leite MLA, Silva FDSCM, Meireles SS, Duarte RM, Andrade AKM. The effect of drinks on color stability and surface roughness of nanocomposites. European Journal of Dentistry.2014 Jul-Sep;3(8):330-336

15. Commission Internationale de l'Eclairage. Recommendations on uniform color spaces, color difference equations, psychometric color terms. Paris. 1978;15:E2-31.

16. Barutcigil Ç, Barutcigil K, Ozarslan MM, Dundar A, Yilmaz B. Color of bulk-fill composite resin restorative materials. J Esthet Restor Dent. 2018 Mar;30(2):3-

17. Vichi A, Ferrari M, Davidson CL.Color and opacity variations in three different resin-based composite products after water aging. Dent Mater. 2004;20(6):530-534.

18. Trevisan TC, Gusson Junior M, Bortolatto JF, Pigossi S, Oliveira Junior OB, Ricci WA. Color stability of conventional and bulk fill composite resins. RG0.2018 Jan-Mar;66(1):15-20.

19. Bagheri R, Burrow MF, Tyas M. Influence of food-simulating solutions and surface finish on susceptibility to staining of aesthetic restorative materials. J Dent. 2005 May;33(5):389-98.

20. Mundim FM, Garcia LFR, Pires-de-Souza FCP.Effect of staining solutions and repolishing on color stability of direct composites. J Appl Oral Sci. 2010 MayJun;18(3):249-54.

21. Domingos PAS, Garcia PPNS, Oliveira ALBM, Palma RGD. Composite resin color stability: influence of light sources and immersion media. J Appl Oral Sci. 2011 May - Jun;19(3):204-11.
22. Barutcigil C, Yildiz M. Intrinsic and extrinsic discoloration of dimethacrylate and silorane based composites. J Dent. 2012 Jul;40:57-63.

23. ErtasE, Guler AU, Yucel AC,, Koprulu H, Guler E. Color stability of resin composites after immersion in different drinks. Dent Mater J.2006 Jun;25(2):371-6

24. Beltrami R, Ceci M,Pani G, Vialba L,Federico R, Poggio C, et al. Effect of different surface finishing/polishing procedures on color stability of esthetic restorative materials: A spectrophotometric evaluation. Eur J Dent. 2018 Jan Mar;:12(1):49-56.

25. Dietschi D, Campanile G, Holz J, Meyer JM. Comparison of the color stability of ten new-generation composites: an in vitro study. Dent Mater. 1994 Nov;10(6):353-362.

26. Topcu FT, Sahinkesen G, Yamanel K, Erdemir U, Oktay EA, Ersahan S. Influence of different drinks on the colour stability of dental resin composites. Eur JDent. 2009 Jan;3(1):50-56

27. Misilli T,GönüloI N. Water sorption and solubility of bulk-fill composites polymerized with a third generation LED LCU. Braz Oral Res. 2017 Sep; 31:e80.

28. Emami N, Sjödahl M, Söderholm KJ. How filler properties, filler fraction, sample 2thickness and light source affect light attenuation in particulate filled resin composites. Dent Mater.2005 Aug;21(8):721-730.

29. MansouriSA,Zidan AZ. Effect of Water Sorption and Solubility on Color Stability of Bulk-Fill Resin Composite.J Contemp DentPract, 2018;19:1129-34.

30. Bolaños VC,Benavides CR, Gonzáles SL, Gonzáles PR, Álvarez PL. Influence of Spectroscopic Techniques on the Estimation of the Degree of Conversion of Bulk-fill Composites. Oper Dent. 2020 Jan - Fev;44(1):92-103.

31. Gonçalves F, Campos LMP, Rodrigues Junior EC, CostaFV, Marques PA, Francci $\mathrm{CE}$, et al. A comparative study of bulk-fill composites: degree of conversion, post-gel shrinkage and cytotoxicity. Braz Oral Res. 2018 Mar;8:32-e17.

32. Luiz BKM, Amboni RDMC, Prates LHM, Bertolino JR, Pires ATN. Influence of drinks on resin composite: Evaluation of degree of cure and color change parameters. Polymer Testing.2007 Jun;26(4):438-44.

33. Samra AP,Pereira SK, Delgado LC, etal. Color stability evaluation of aesthetic restorative materials. Braz Oral Res. 2008;22:205-10.

34. Schroeder T,Da Silva PB, Basso GR, Franco MC, Maske TT,Cenci MS. Factors affecting the color stability and staining of esthetic restorations. Odontology. 2019 0ct;:107(4):507-12

\section{Renata Siqueira Scatolin} (Corresponding address)

Herminio Ometto University Center, School of Dentistry, Araras, Brasil.

Dr. Maximiliano Baruto Avenue, 500 - Jd. Universitario, Araras - SP, 13607-339.

Date submitted: 2020 Jun 16

E-mail: re_scatolin@hotmail.com 